\title{
FELICIDADE INTERNA BRUTA: UM ENFOQUE NA INTELIGÊNCIA EMOCIONAL
}

\author{
SANTOS JUNIOR, Norival José dos ${ }^{1}$ \\ DIAS, Yan Caxias ${ }^{2}$ \\ FIGUEIREDO, Mari Lucia ${ }^{3}$
}

doi》 10.33726/akdpapers2447-7656v9a62020p16-36

RESUMO: Este estudo teve como objetivo principal destacar a Inteligência Emocional como uma ferramenta eficaz na busca da felicidade no ambiente de trabalho. Pretendeu-se também, possibilitar a compreensão da evolução do conceito de "Inteligente" para o de Inteligência Emocional. A metodologia adotada foi a da revisão bibliográfica sobre o tema Inteligência Emocional, com ênfase na área do trabalho. Justifica a pesquisa, o fato de que as emoções e suas respectivas inteligências vêm ganhando espaço no mundo coorporativo e como essas pessoas podem desenvolver está competência para favorecer seu desempenho profissional. Como resultados, concluímos que o Quociente Intelectual (QI), sozinho, não é suficiente para alavancar carreiras organizacionais.

PALAVRAS-CHAVE: Inteligência emocional, trabalho, felicidade, carreira

ABSTRACT: This study aimed to highlight Emotional Intelligence as an effective tool in the pursuit of happiness in the workplace. It was also intended to enable the understanding of the evolution of the concept of "Intelligent" to that of Emotional Intelligence. The methodology adopted was the literature review on the theme Emotional Intelligence, with emphasis on the area of work. Justifying the research, the fact that emotions and their respective intelligences are gaining space in the corporate world and how these people can develop is competence to favor their professional performance. As a result, we conclude that the Intellectual Quotient (IQ) alone is not sufficient to leverage organizational careers.

KEYWORDS: Emotional intelligence, job, happiness, career

\footnotetext{
${ }^{1}$ Graduando do curso de Administração. E-mail: norivalbrmc@hotmail.com

${ }^{2}$ Graduando do curso de Administração. E-mail: yan.dias20151995@gmail.com

${ }^{3}$ Psicóloga, doutora em avaliação psicológica, docente da UEMG- Frutal
} 


\section{INTRODUÇÃO}

O trabalho é de extrema importância na vida do ser humano e ocupa grande parte de nossa existência. Nele, passamos um tempo considerável de nossa trajetória realizando as atividades laborais que escolhemos, para que, assim, tenhamos a oportunidade de aproveitar os frutos de tudo aquilo que realizamos profissionalmente (MARQUES, 2018).

Por se tratar de algo que justamente ocupa um espaço significativo em nossa vida, precisamos lidar com o cenário do trabalho, e com tudo que 0 envolve, da melhor maneira possível, pois somente assim poderemos ter os resultados positivos que tanto desejamos durante nossa evolução profissional, argumenta o autor. E, além disso:

No mundo globalizado em que estamos vivendo, em razão dos grandes avanços tecnológicos, da intensa competitividade no mercado, das mudanças constantes no ambiente organizacional e até mesmo da falta de tempo para o lazer na nossa rotina, as pessoas tendem a sofrer mais com o stress no seu dia a dia. Com isso, se torna cada vez mais necessário aprendermos a administrar e controlar nossas emoções para termos uma melhor qualidade de vida (JUNQUEIRA; COUTO; PEREIRA, 2011, p. 01).

Um dos temas que têm mais instigado pesquisadores na contemporaneidade corporativa é a inteligência e a emoção, posto que venham gerando polêmicas por mais de um século de estudos e pesquisas (MATHEUWS; ZEIDNER \& ROBERTS, 2002). A relevância disso, talvez, se volte ao contexto em que "As concepções atuais sobre inteligência constituem o produto do pensamento, trabalho e investigações de centenas de pesquisadores, que ao longo da história, definiram o que é ser inteligente" (WOYCIEKOSKI \& HUTZ, 2009, p. 01).

Tais autores afirmam que, assim como atualmente é possível perceber as evoluções no pensamento em muitas áreas, também tem sido levantada a necessidade de se repensar 0 que se entende por inteligência e por comportamento inteligente. A verificação das relações entre cognição e emoção poderia resultar no reconhecimento da capacidade do homem em lidar 
com seu mundo emocional de forma inteligente, compatível com seus objetivos mais amplos de vida (WOYCIEKOSKI \& HUTZ, 2009).

Entretanto, Goleman (2017) argumenta que no campo organizacional, apenas as capacidades cognitivas não são suficientes para a garantia de sucesso na vida, pois se estima que o Quociente de Inteligência (QI), que é a capacidade de compreender e manipular símbolos matemáticos e linguísticos é responsável por $20 \%$ dos fatores que determinam o sucesso, restando $80 \%$ para variáveis não especificadas, que vão desde a classe social até a margem da mera sorte.

Nesse percentual, pode-se acrescentar o Quociente Emocional (QE), cujos aspectos fundamentais propostos pelo autor são: autoconsciência, autocontrole, consciência social e a habilidade de gerenciar relacionamentos, postos como elementos que conduzem ao sucesso profissional.

\section{A HISTÓRIA DA INTELIGÊNCIA EMOCIONAL}

Em 1920, o renomado psicólogo Edward Thorndike descreve o conceito de "Inteligência Emocional", como sendo a habilidade de entender e controlar/administrar as emoções para agir de forma mais sensata nas relações humanas.

David Wechsler, por sua vez, sugeriu, em 1940, que outros fatores além da habilidade intelectual estão envolvidos em um comportamento inteligente. Já os psicólogos humanistas, assim como Abraham Maslow, no ano de 1950, descreveram como as pessoas poderiam construir força emocional.

Howard Gardner, então, publicou o livro Estruturas da Mente - Teoria das Inteligências Humanas (1980). E, de acordo com Gardner, os seres humanos possuem diferentes formas de processamento de informações e estes meios são relativamente independentes uns dos outros. No entanto, a introdução do termo "Inteligência Emocional", foi relatada por Wayne Payne, em 1985, em sua Tese de Doutorado, chamada: Um estudo da emoção: desenvolvendo a inteligência emocional.

Nessa sequência histórica, vemos que a primeira formulação do que veio a ser inteligência emocional do modo como a temos hoje, foi proposta 
pelos psicólogos John Mayer e Peter Salovey, das Universidades de New Hampshire e Yale, respectivamente. Porém, foi por meio dos trabalhos de Daniel Goleman, que o conceito foi disseminado (MACIEL \& SÁ DE SOUZA, 2016, p. 06).

A pesquisa de Mayer e Salovey buscava refutar a ideia de que a inteligência poderia ser medida apenas pelos testes de QI para determinar fatores de previsão de sucesso para a vida, visto que tais testes contemplavam aptidões linguísticas e matemáticas apenas (GOLEMAN, 2017).

Para eles, a inteligência possuía uma visão mais ampla. Assim propuseram uma visão de inteligência emocional expandindo as aptidões em cinco domínios: (i) conhecer as próprias emoções; (ii) lidar com as emoções; (iii) motivar-se; (iv) reconhecer emoções nos outros; e, (v) lidar com relacionamentos.

Até a década de 1990, acreditava-se que o QI (Quociente Intelectual) determinava o sucesso profissional e até pessoal de um indivíduo, daí as empresas se basearem em testes, em que se identificavam o QI de seus líderes e empregados (SILVA et al, 2014). Porém, com a evolução da ciência, assim como da psicologia, da psiquiatria e atualmente da neurociência, foi se descobrindo que existiam diferentes fatores a determinar o sucesso de pessoas e organizações, chegando-se ao QE (Quociente Emocional), conceito em que se verifica que a inteligência emocional também se torna imprescindível neste processo (GOLEMAN, 2017).

O autor ressalta que o controle das emoções pode trazer transformações significativas, tanto no ambiente profissional quanto familiar, uma vez que o indivíduo se torna mais consciente de suas responsabilidades sobre o bem estar, sobre a sua felicidade de si mesmo e de outrem, usando as habilidades adquiridas para promover uma mudança cultural e social no meio em que vive e ou trabalha.

Para Goleman (2001, p. 338) "a Inteligência Emocional contém cinco competências emocionais e sociais básicas, que são classificadas por ele como: autopercepção, autorregulamentação, motivação, empatia e habilidades sociais". A autopercepção significa que a pessoa compreende e manipula de forma consciente suas emoções para desenvolver um comportamento correto 
diante da situação enfrentada. Já, a autorregulação, se refere ao nosso autocontrole, ou seja, a nossa capacidade de usar nossas emoções de modo a facilitar o bom desenvolvimento do dia-a-dia de nossas vidas. Quanto à motivação, é a capacidade da pessoa de dirigir suas emoções a serviço de um determinado objetivo. A empatia percebe os seus anseios e trabalha-os de forma positiva para que, com isso, consiga cultivar sintonia com o maior número de pessoas possível. E, por fim, o autor ressalta que a habilidade social se caracteriza pela desenvoltura em relacionamentos interpessoais.

Outras contribuições que podemos ressaltar foram dos psicólogos Louis Thurstone (1887-1956) e Howard Gardner, mesmo de épocas distintas, ambos defendem que a inteligência seria composta por um conjunto de mecanismos que atuam isoladamente no cérebro (GANDRA, 2016).

Thurstone (1938) faz uma crítica à inteligência geral de Spearman, afirmando que a inteligência pode ser dividida em diversas competências básicas baseadas em sete fatores: a compreensão verbal, a aptidão numérica, a visualização espacial, a memória, o raciocínio e velocidade perceptiva, e que estes mesmos fatores são suscetíveis de serem avaliados através do teste de Capacidades Mentais Básicas (WOICIEKOSKI e HUTZ, 2009).

A teoria das inteligências múltiplas foi criada por Gardner, em 1981, afirmando que elas seriam independentes entre si e que atuariam em locais separados do cérebro, sob a obediência de regras próprias, sendo elas a inteligência lógica matemática, a linguística, a musical, a espacial, a corporal, a cenestésica, a intrapessoal e interpessoal. Estas, portanto, "Foram as que serviram de base para a definição da inteligência emocional" (MAVROVELI et al., 2009, p. 263).

Entretanto, emoção e inteligência têm sido, muitas vezes, compreendidas como contrapontos adversários. Para Gardner (1995) e Mayer Salovey (1997), as emoções são tidas como aspecto substancialmente irracional e instância perturbadora do pensamento. "Essa concepção percebe a mente humana e sua inteligência por um prisma unidimensional, que valoriza apenas o fator racional da inteligência e o coloca em primeiro plano" (GOMES \& SIQUEIRA, 2010, p. 30). 
Para Weisinger (2001, p. 14), "o uso inteligente das emoções, isto é, fazer intencionalmente com que suas emoções trabalhem a seu favor, o ser humano usaria como uma ajuda para ditar seu comportamento e seu raciocínio, de maneira a aperfeiçoar seus resultados". O que evidencia que a inteligência emocional é a capacidade de administrar as emoções de forma produtiva para o alcance de objetivos. É saber lidar com medos, inseguranças e insatisfações em benefício próprio. É ter habilidade no convívio com as outras pessoas reagindo de maneira controlada e desenvolvendo, assim, um ambiente harmonioso e, ao mesmo tempo, produtivo em resultados.

Para Fonseca et. al. (2016), a inteligência emocional, assim como todas as outras competências, pode ser desenvolvida pelo profissional. Após identificar os pontos fracos emocionais e comportamentais que mais prejudicam o desempenho do indivíduo é preciso centrar forças para desenvolvê-los. Estes autores afirmam que é necessário enxergar e aproveitar todas as situações do dia a dia como oportunidades para praticar o treinamento.

Pedir feedbacks aos colegas, superiores, subordinados e clientes, pode ajudar a descobrir o que as pessoas pensam e o que profissional precisa melhorar. "O indivíduo deve dar prioridade aos aspectos que são mais fáceis e rápidos, ciente que mudar hábitos de comportamento pode ser um processo de longo prazo" (FONSECA et al 2016 p. 14). Portanto, quanto mais as cinco habilidades da inteligência emocional forem praticadas, os velhos hábitos serão substituídos e os novos vivenciados de forma espontânea. O profissional com esta competência tem mais chances de ampliar sua empregabilidade.

Todavia, para que possamos compreender a IE é necessário que se tenha claro a concepção de emoção. Além disso, o próprio aspecto multidimensional das emoções ocasionaria uma concepção de IE complexa, Matthews et al. (2002).

Para Fortes D'Andrea (1996), poucos fatos psicológicos se comparam com as emoções, pois elas demarcam fatos importantes em nossa vida, mas, mais do que isso, elas influenciam a forma como reagimos a estas experiências. Woiciekoski e Hutz, (2009 p. 03), argumentam que a emoção seria uma reação psicobiológica complexa, que envolveria a "inteligência e 
motivação, impulso para ação, além de aspectos sociais e da personalidade, que acompanhados de mudanças fisiológicas, expressariam um acontecimento significante para o bem-estar subjetivo do sujeito no seu encontro com 0 ambiente".

Estudos e pesquisas o tema apontam que as competências emocionais são essenciais para a adaptação, por isso, tem surgido o interesse pelo tema da inteligência emocional e têm surgido muitos programas de aprendizagem social e emocional em escolas e em ambientes de trabalho.

A emoção também pode ser entendida, portanto, como sendo uma alteração fisiológica desencadeada por estímulos externos, e que surge em resposta a tais eventos externos perturbadores (ATKINSON et al. 2002).

Para Damásio (1996), quando o sujeito, após perceber um estímulo que, de alguma maneira o afeta, sofre alterações fisiológicas importantes, como angústia, falta de ar, palpitações etc. E é precisamente o reconhecimento desses sinais (pelo cérebro) que gera a emoção.

Com relação ao entendimento da inteligência emocional, podemos descrever o seguinte:

A inteligência emocional envolve a capacidade de perceber acuradamente, de avaliar e de expressar emoções; a capacidade de perceber e/ou gerar sentimentos quando eles facilitam 0 pensamento; a capacidade de compreender a emoção e o conhecimento emocional; e a capacidade de controlar emoções para promover o crescimento emocional e intelectual (MAYER e SALOVEY 1997, p. 15).

Podemos citar alguns estudos de inteligência emocional que utilizaram instrumentos de medidas validados, enquanto que outros elaboraram questões a partir das teorias sobre o assunto, então vigentes na literatura.

Entre esses, podemos apresentar os trabalhos de Diório (2001), que avaliou a competência emocional de gestores. O de Nascimento (2006) investigou as relações entre inteligência emocional e bem-estar no trabalho. Já, Marcondes (2008) buscou conhecer as relações entre inteligência emocional e bem-estar no trabalho de funcionários públicos. Gomes e Siqueira (2010), por sua vez, descreveram e analisaram as relações entre as cinco habilidades de 
inteligência emocional (autoconsciência, automotivação, autocontrole, empatia e sociabilidade) em estudantes universitários. Também, Santos (2014) investigou de que forma a inteligência emocional dos empregados de empresas de base tecnológica se relaciona com o conflito da tarefa que desempenham, bem como com a auto eficácia. Fonseca et al (2016) mostraram que, dentre todas as competências exigidas, a inteligência emocional ganha destaque como diferencial no controle psíquico e comportamental dos colaboradores, trazendo ganhos para as empresas no alcance de metas e objetivos. E, por fim, Tavares (2013) verificou a existência de uma relação entre inteligência emocional e a satisfação no trabalho num contexto organizacional onde o valor central é a hospitalidade.

De acordo com Serra (2004, p. 33), a teoria de Goldeman defende que "a inteligência está ligada à forma como lidamos com as nossas emoções", ressaltando que o controle das emoções pode trazer transformações significativas, tanto no ambiente profissional quanto familiar, uma vez que 0 indivíduo se torna mais consciente de suas responsabilidades sobre o bem estar, sobre a sua felicidade de si mesmo e de outrem, usando as habilidades adquiridas para promover uma mudança cultural e social no meio em que vive e ou trabalha. A inteligência emocional envolve a capacidade de perceber acuradamente, de "avaliar e de expressar emoções; a capacidade de perceber e/ou gerar sentimentos quando eles facilitam o pensamento; a capacidade de compreender a emoção e o conhecimento emocional; e a capacidade de controlar emoções para promover o crescimento emocional e intelectual" (GARCIA, 2015, p. 15).

Na teoria de Gardner, ressalta Bourscheid (s/d), o papel das emoções é pouco explorado, sendo que nos estudos que ele realizou, não se investigou a função do sentimento nas inteligências. Uma vez que o campo das emoções também se estende além da linguagem e da cognição, seu estudo é de extrema relevância. Outros cientistas cognitivos que explicam como a mente processa a informação não levam em conta o fato de que a racionalidade da mente é guiada pela emoção. Porém, Woyciekoski \& Hutz (2009, p. 03) colaboraram, argumentando que a emoção seria uma reação psicobiológica complexa, que envolveria "inteligência e motivação, impulso para ação, além 
de aspectos sociais e da personalidade, que acompanhados de mudanças fisiológicas, expressariam um acontecimento significante para o bem-estar subjetivo do sujeito no seu encontro com o ambiente".

Costa (2017) ressalta a importância da Inteligência Emocional na administração das emoções no ambiente corporativo, e esta importância está associada ao fato das pessoas serem o recurso mais importante dentro do sistema produtivo, pois, as pessoas pensam, agem e monitoram seus procedimentos levando em conta o ambiente em que vivem.

Outro autor que contribuiu com essa teoria é Ryback (2004, p. 66), destacando que a Inteligência Emocional permite uma "relação equilibrada entre o intelecto e a emoção no local de trabalho, de forma que a percepção emocional ajuste-se com o processo de tomar decisões a cada momento".

Portanto, a Inteligência Emocional ajuda no ambiente de trabalho, tanto o funcionário quanto a empresa para lidarem de forma correta com diversas situações. Para o trabalhador: maior autoconfiança; menos estresse e preocupações; mais alegria e satisfação; menos frustrações e raiva; mais cooperação e compreensão; mais aptidão para manter conversas difíceis; capacidade de assumir riscos saudáveis. Já, para a empresa: melhora do trabalho em equipe; superação das mudanças; mais comprometimento, envolvimento e motivação; maior flexibilidade; menos queixas; mais criatividade, receptividade, franqueza e confiança; mais produtividade (GARDENSWARTZ et al, 2012).

Corroborando essas ideias, no pensamento contemporâneo sobre a Inteligência Emocional, a emoção é considerada como um dos principais fatores responsáveis pelo funcionário encontrar sentido e propósito no trabalho, (GRAY \& ANNIS, 2013). Como um fator de favorecimento na construção da identidade profissional, levando o funcionário a um forte investimento afetivo para um bom desempenho (ZANELLI et al, 2014); melhorando a comunicação, aumentando a satisfação e criando uma atmosfera mais positiva no ambiente de trabalho (CHAPMAN \& WHITE, 2012).

Dados apresentados pelo Center for Creative Leadership, em 1970, apontam que a Inteligência Emocional equilibra as emoções, afeta a lucratividade e o desempenho e, além disso, o fracasso na carreira envolve 
deficiências na competência emocional. Noutra publicação, a Haward Business Review, de 1980, relaciona as emoções como um fator importante no desempenho do trabalho e na influência dos sentimentos, tais como a felicidade, a qual é necessária para lidar com situações difíceis (GARDENSWARTZ et al, 2012).

\section{FELICIDADE INTERNA BRUTA (FIB)}

O ser humano, com seu desejo de descobrir o novo e medir tudo o que está ao eu redor, cria e recria com o passar do tempo novas ideias e práticas. Em meados de 1947, por exemplo, o surgimento do Produto Interno Bruto (PIB) disseminou mundialmente $\mathrm{O}$ uso de indicadores econômicos para medir 0 progresso de um país. E, partir da década de 60, ascende nos Estados Unidos uma nova ideologia, que buscava deslocar o foco de aspectos meramente econômicos para contemplar parâmetros que pudessem aferir o bem estar da população. Nasciam, aí, os "indicadores sociais" (SALES et al, 2012, p. 02).

$\mathrm{Na}$ década de 70, então, surge um novo indicador sistêmico, desenvolvido no reino Butão, um pequeno país localizado na Ásia, com o apoio do Programa das Nações Unidas para o Desenvolvimento (PNUD): o índice de Felicidade Interna Bruta (FIB). Tal Índice de Felicidade Bruta mede o progresso da sociedade a partir das seguintes dimensões: padrão de vida, educação, saúde, governança, cultura, vitalidade comunitária, resiliência ecológica, uso equilibrado do tempo e bem-estar psicológico. É notório o desenvolvimento desse apontador, tornando-se mundialmente conhecido, ajustando a outros tantos medidores sociais: o Índice de Liberdade Humana (ILH), Índice de Liberdade Política (ILP), Índice de Pobreza Humana (IPH).

Logo, a criação do FIB gerou certo interesse na comunidade internacional, resultando em vários trabalhos econômicos voltados para o seu conceito e para a eficácia de sua fórmula de cálculo. Dentre os muitos surveys que incluem perguntas sobre felicidade e satisfação com a vida, destacam-se: o "Gallup World Poll", com mil entrevistados, em 160 países; a "World Values Survey", que, na coleta de 2011/2012, entrevistou mais de 84 mil pessoas, em 56 países; a americana "General Social Survey", com amostra de 55 mil 
indivíduos; a "Eurobarometer", da União Europeia, que entrevista mil cidadãos de cada estado-membro; a "The World Happiness Report", de 2013, com entrevistados em 156 países; a "Happy Planet Index", de 2012, com amostras de 151 países; a publicação "How's Life - Measuring Well Being", de 2013, do projeto Better Life, da OCDE, com dados dos 34 países-membros, além de Brasil e Rússia; a "Latinobarómetro", com abrangência de 18 países latinoamericanos (além da Espanha), e 23 mil entrevistados; e a "Beyond Facts: Understanding Quality of Life", do Banco Interamericano de Desenvolvimento (BID), que classificou 23 países latino-americanos e caribenhos no estudo de 2008.

Infelizmente o Brasil não possui uma pesquisa nacional contínua, nem oficial, assim, qualquer trabalho de análise por comparação entre a melhor pesquisa que temos a "Well Being Brazil Index", da FGV (Fundação Getúlio Vargas), e o PIB (Produto Interno Bruto) ou o IDH (Índice de Desenvolvimento Humano) torna-se impossível ou pouco robusto (BRANCO, 2015, p. 10).

Em 2009, a monja hinduísta Susan Andrews, do Instituto Visão Futuro, em entrevista à Folha $U O L$, revelou que tinha desenvolvido uma versão brasileira do questionário, mas este ainda seria aplicado em projetos-piloto no Estado de São Paulo, e acrescentou que "FIB não é meramente um indicador: é também um catalisador de mudança, um processo de mobilização social em prol do bem-estar coletivo e do desenvolvimento sustentável, visado o bemestar de todos" (SUSAN ANDREWS, 2009).

Herculano (2000), afirmou que o uso de indicadores auxilia nas comparações entre dois ou mais objetos de estudo, em virtude das informações condensadas, simplificadas e quantificadas que fazem parte de sua composição. Estas informações, por sua vez, podem ser de natureza econômica (quantitativa) ou de natureza social (qualitativa).

Para Sandroni (1987), esses indicadores podem sofrer mudanças e oscilações, já que são constituídos de dados estatísticos capazes de oferecer uma ideia do estado de uma determinada economia, num certo período ou data. Porém, segundo a ONU (Organização das Nações Unidas), os indicadores sociais são dados construídos com base em observações, referentes a aspectos da vida social ou a mudanças nela ocorridas. 
Neste propósito, o objetivo central desse estudo é o Índice da Felicidade Interna Bruta, um indicador inovador, cujo papel principal é medir o bem estar de uma população a partir de sua felicidade manifesta.

A seguir apresentaremos os nove pilares do indicador FIB:

(i) Bem-estar; Saúde; Equilíbrio do Tempo; Boa Governança; Vitalidade Comunitária; Educação; Diversidade Cultural; Ecológica; Padrão de Vida. E, dentro dessa linha de pensamento, Jens Asendorpf, em 2004, avança para o significado do conceito "bem-estar", cuja denominação divide-se em um elemento cognitivo, chamado satisfação com a vida, e outro afetivo, chamada felicidade. Esta última, ainda se divide em afetividade positiva e afetividade negativa. Segundo as concepções teóricas referentes ao bem-estar psicológico, as bases para as formulações psicológicas são o desenvolvimento humano e a capacidades para enfrentar os desafios da vida. O bem-estar psicológico e, principalmente, espiritual, também pode se mostrar como um recurso interno de alívio para pessoas forçadas a se adaptar à incerteza relacionada a problemas de saúde no longo prazo, como: diabetes mellitus, câncer, entre outras endemias crônicas (LANDIS, 1996). Diante dos pontos sugeridos acima, seria pouco provável a criação de um apontador social abrangente que não fizesse o uso da abordagem tácita da paz de espírito do ser humano (SALES et al, 2012, p. 05).

(ii) Já, a Saúde, mede a eficácia das políticas de saúde, com critérios como autoavaliação da saúde, invalidez, padrões de comportamento arriscados, exercícios, sono, nutrição etc.

(iii) A gestão equilibrada do tempo é avaliada, incluindo tempo no trânsito, no trabalho, nas atividades educacionais, etc.

(iv) Vitalidade Comunitária foca nos relacionamentos e interações nas comunidades. Examina o nível de confiança, a sensação de pertencimento, a vitalidade dos relacionamentos afetivos, a segurança em casa e na comunidade, a prática de doação de voluntariado.

(v) A Educação leva em conta vários fatores como participação em educação formal e informal, competências, envolvimento na educação dos filhos, valores em educação, educação ambiental etc.

(vi) Entretanto, a cultura avalia as tradições locais, festivais, valores nucleares, participação em eventos culturais, oportunidades de desenvolver capacidades artísticas, e discriminação por causa de religião, raça ou gênero.

(vii) O meio ambiente mede a percepção dos cidadãos quanto à qualidade da água, do ar, do solo, e da biodiversidade. Os indicadores incluem acesso a áreas verdes, sistema de coleta de lixo, etc.

(viii) Outro indicador importante é a governança, donde se avalia como a população enxerga o governo, a mídia, o judiciário, o sistema eleitoral, e a segurança pública, em termos de responsabilidade, honestidade e transparência. Também mede a cidadania e o envolvimento dos cidadãos com as decisões e processos políticos.

(ix) E, por último, o padrão de vida, que avalia a renda individual e familiar, a segurança financeira, o nível de dívidas, a qualidade das habitações (LUSTOSA \& MELO, 2010, p. 37-38). 
As dimensões do FIB são norteadoras quanto à construção de instrumentos que visam circunstâncias diversas da vida dos cidadãos. "Esse método vem conquistando adeptos ao redor do mundo, tanto na esfera pública quanto no âmbito das organizações não governamentais e empresas privadas, por trazer a felicidade pautada na qualidade de vida como indicador de desenvolvimento" (PORTO \& MEDEIROS, 2017).

Para Welsch (2009), as respostas à felicidade estão correlacionadas com as reações físicas que podem validar a felicidade interna: as pessoas que relatam ser felizes tendem a sorrir mais e mostrar níveis mais baixos de respostas ao estresse (frequência cardíaca, pressão arterial), e elas são menos propensas a cometer suicídio. Bem intencionadas ou rotuladoras, a felicidade é qualificada como substantivo feminino que indica qualidade ou estado de feliz, satisfação, júbilo, contentamento, bem-estar, boa fortuna e sorte (HOUAISS; VILLAR, 2009).

Ainda definindo o conceito, a literatura considera a felicidade como indicador de bem-estar subjetivo (DIENER, 2006; LYUBOMIRSKY \& LEPPER 1999), sendo, neste sentido, confundível com outras medidas deste tipo: Veenhoven $(1997 ; 2000)$ refere que felicidade, satisfação com a vida, qualidade de vida, bem-estar, denotam o mesmo significado e são utilizados como sinônimos. Felicidade, então, pode significar prazer, satisfação com a vida, emoções positivas, vida plena, ou sensação de contentamento, entre outros (DIENER et al, 2003). Daí, surge a indagação: porque a felicidade tem tantos sentidos, quer seja na linguagem popular quanto na acadêmica?

Diener (2006) diz que, tanto pode representar as causas como os efeitos, pode significar humor geral positivo, avaliação global de satisfação com a vida, viver uma boa vida, ou as causas que fazem as pessoas felizes no seu contexto de vida (PAIS-RIBEIRO, 2012).

$\mathrm{E}$, sem pretender esgotar os aspectos conceituais relativos à felicidade interna bruta, é necessário apresentar algumas considerações que justifiquem a identificação com a proposta do nosso estudo.

Assim, Ferentz (2018) elaborou um estudo cujo objetivo foi o de apresentar as possibilidades que a percepção da população pode trazer quando utilizada em conjunto com as metas para o desenvolvimento urbano. A 
aplicação da pesquisa se deu por meio do método de FIB, aplicando-se 425 questionários estratificados. Os resultados apresentaram que o FIB de Curitiba está em uma classificação entre "regular" e "feliz", baseando-se em uma escala de Likert de 05 pontos.

Em outro estudo, aplicaram-se um questionário de FIB, na cidade de Lavras - MG, para avaliar se aspectos como sexo, idade, escolaridade e localização geográfica podem implicar em diferentes níveis de felicidade dos indivíduos. Os resultados obtidos revelaram que as pessoas residentes nesta cidade apresentam níveis distintos de felicidade, de acordo com o seu sexo, idade, escolaridade e região que residem (SALES et al 2012).

No sítio eletrônico da Secretaria de Planejamento do Estado de Goiás, consta o trabalho de Lustosa e Melo (2014) acerca da Felicidade Interna Bruta, tida como índice de desenvolvimento sustentável, denotando a disseminação da ideia perante o setor público.

A empresa Icatu-Hartford, administradora de fundos de investimento e planos de previdência, foi uma das primeiras a adaptar o questionário baseado nas premissas do FIB, baseando-se em quatro pilares conceituais: corpo, mente, bolso e mundo (LOES, 2014).

Outro destaque é a empresa Natura, primeira empresa no mundo a trabalhar com o conceito de "FIB empresarial", potencializando a atuação da responsabilidade socioambiental no setor privado com a proposta de aumento do bem-estar (PORTO \& MEDEIROS, 2017).

Podemos inferir que, pela semelhança de conteúdo e as ideias defendidas por Daniel Goleman, em seu best-seller "Inteligência Emocional", que a Inteligência Emocional é uma necessidade que precisa ser satisfeita para que se alcance o bem-estar. Dentro dessa mesma linha de valorizar, Boyce e Wood (2010) atestaram em seus estudos a importância da terapia para o bemestar subjetivo. Para eles, a parte emocional exerce um forte impacto positivo na avaliação da felicidade.

Com base em suas pesquisas, esses estudiosos compararam o impacto do aumento de renda com um tratamento psicológico e foram taxativos: o tratamento psicológico é 32 vezes mais impactante que o aumento da renda no nível de felicidade das pessoas. 


\section{CONSIDERAÇÕES FINAIS}

A inteligência emocional é um dos conceitos psicológicos mais populares e recentes desta última década. Acredita-se que ela esteja associada à capacidade das pessoas de perceber e gerenciar suas próprias emoções, assim como perceber e, porque não, conduzir as dos outros. Sua rápida absorção pela sociedade deve-se à crença de que a IE está relacionada tanto ao bem-estar do indivíduo quanto ao seu sucesso profissional.

Há até pouco tempo atrás, o mundo acreditava que era o quociente intelectual (Q.I) do ser humano o único responsável pelo seu sucesso e conquistas no âmbito profissional. Porém, com o passar do tempo, e após alguns estudos realizados por psicólogos como Gardner, Mayer e Salovery, ficou comprovado que pessoas que têm um Q.I. elevado não são, obrigatoriamente as mais bem sucedidas profissionalmente. Na realidade, os melhores resultados neste assunto, são de indivíduos com um grande controle de suas habilidades emocionais, mesmo que apresentando um Q.I. mediano. Esta tese foi, posteriormente, amplamente difundida através do livro Inteligência Emocional, de Daniel Goleman.

O ser humano dispõe de várias nuances de personalidade e emoções distintas. Cada ser se torna diferente uns dos outros, cada qual com suas características peculiares e personalidades distintas, diferentes formas de vivenciar as emoções, anseios, desejos, sonhos e vontades individuais anteriores a cada indivíduo. E, neste mundo globalizado, no qual se vive, o mercado de trabalho se encontra em mudanças constantes, notando-se novos critérios de seleção para adentrar neste mercado.

Efetivamente, Platão já dizia que toda a aprendizagem assenta numa base emocional. E possivelmente tinha razão. "Quem tem inteligência emocional é confiante, focado, adaptável e flexível. Recupera rapidamente do estresse e é resistente", resumiu o psicólogo norte-americano Daniel Goleman. Um profissional que tem a Inteligência Emocional desenvolvida, normalmente tem maior autoconhecimento, compaixão, empatia, confiança, flexibilidade, resiliência e atitude positiva. 
Estudos sobre psicologia positiva sugerem que a compaixão, a empatia, o altruísmo e a atitude positiva produzem a sensação felicidade. Arriscamos compilar todas essas ideias e dizer que felicidade é um sentimento, um estado de espírito, uma cosmovisão, uma atitude de gratidão e se reflete na maneira que gerimos as nossas emoções.

Corrobora essa impressão e se alinha com o nosso objetivo de estudo, que foi $o$ de destacar a inteligência emocional e a felicidade como uma ferramenta eficaz no ambiente de trabalho.

O tema da Inteligência Emocional não é novidade na literatura, porém, a ausência de trabalhos que desenvolvem a felicidade e as emoções são quase inexistentes. Esse foi o primeiro problema diante do qual esbarramos. Mas, apesar das dificuldades, o conceito de FIB é promissor, e tem conquistado espaço na academia e nos meios políticos, como ferramenta de diagnóstico e prognóstico das efetivas condições de vida da população. Esta constatação enseja estudos mais aprofundados.

Nos últimos anos, o tema Felicidade tornou-se presença importante, não só em reportagens jornalísticas, mas principalmente na pesquisa acadêmica em Psicologia. Portanto, na contramão dos valores de uma sociedade cada vez mais materialista e tecnicista, tais eventos mostram que o conceito de Felicidade está muito mais associado à Qualidade de Vida do que à riqueza e aos bens materiais.

Todos buscam um nível básico de conforto e segurança financeira para a velhice, mas, além de certo patamar, há muita evidência de que posses e dinheiro não estão associados ao bem estar.

O que sim, está ligado ao tema da Felicidade, é o conceito de Inteligência Emocional, ou seja, nossa capacidade de autoconhecimento, saber manejar as emoções e nos relacionarmos bem, conseguindo agir com sabedoria e generosidade. Isso mesmo, pessoas generosas são mais felizes.

Outra questão tratada no trabalho refere-se à adaptação hedônica como "o processo psicológico pelo qual as pessoas se acostumam com um estímulo positivo ou negativo, de forma que os efeitos emocionais do estímulo sejam atenuados ao longo do tempo" (LYUBOMIRSKY, 2010, p. 201). Este processo 
relativiza a importância de variáveis econômicas e não econômicas consideradas óbvias para o estudo de felicidade.

Para Kahneman (2011), por exemplo, a "saúde física" é muito importante, mas ele considera que a adaptação hedônica minimiza o impacto de vários problemas de saúde, como a deficiência física causada por um acidente, dessa forma, o nível de felicidade do indivíduo não é tão afetado por conta dessas condições.

Sabemos que a ausência de transtornos mentais não é suficiente para que o indivíduo floresça, para que tenha uma percepção de sua existência como feliz ou plena de sentido. A felicidade é uma condição que difere quantitativamente da ausência de infelicidade. 


\section{REFERÊNCIAS}

ANDREWS, S. Entrevista para Folha UOL. São Paulo, 2009.

ATKINSON, A. A. et al. Contabilidade Gerencial. Tradução André Olímpio Mosselman Du Chenoy Castro; revisão técnica Rubens Famá. São Paulo: Atlas, 2002.

BOYCE, C.; WOOD, A. Money or Mental Health: The Cost of Alleviating Psychological Distress with Monetary Compensation versus Psychological Therapy. Health Economics, Policy and Law, v. 5, p. 509-516, 2010.

BOURSCHEID, A. T. S. Inteligência emocional. Mimeo, s/d.

BRANCO, V. C. R. Felicidade interna bruta: como escolher os índices do século XXI. Universidade de Brasília - UnB Faculdade de Ciências Econômicas - FACE Departamento de Economia. Monografia, 2015.

CHAPMAN, G.; WHITE, P. As cinco linguagens da valorização pessoal no ambiente de trabalho. Tradução: Emirson Justino. São Paulo: Mundo Cristão, 2012.

COSTA, I. L. A importância da inteligência emocional para os processos de ensino e aprendizagem: impactos pedagógicos. 2017. 34 f. TCC (Graduação) - Curso de Pedagogia, Universidade Federal do Rio Grande do Norte, Natal, 2017.

CLONINGER, C.R. Feeling good: the science of well-being. Oxford University Press: New York, 2004.

DAMÁSIO, A. R. O Erro de Descartes: Emoção, Razão e Cérebro Humano (25ㄹed.) Mem Martins: Publicações Europa-América, 1996.

DIENER, E.; OISHI, S.; LUCAS, R.E. Personality, culture, and subjective wellbeing: emotional and cognitive evaluations of life. Annu Rev Psychol, 54: 403-425, 2003.

DIENER, E. Guidelines for national indicators of subjective well-being and ill-being. Applied Research in Quality of Life, 1, 151-157, 2006.

DIÓRIO, S. Competência emocional de gestores. Dissertação (Mestrado em Administração) - Faculdade de Administração, Universidade Metodista de São Paulo: São Bernardo do Campo, 2001.

FERENTZ, L. M. S. Análise da felicidade interna bruta: estudo piloto na cidade de Curitiba. DRd Desenvolvimento Regional em debate. v. 8, n. 1, p. 164-181, jan./jun. 2018.

FERRAZ, R.B. et al. Felicidade: uma revisão. Rev. Psiq. Clín 34(5); 234-242, 2007

FONSECA, L. et. al. Inteligência emocional - uma competência da atualidade. INOVARSE - XII Congresso Nacional de Excelência em Gestão \& III INOVARSE 
Responsabilidade Social Aplicada, 2016.

FORTES D'ANDREA, F. Desenvolvimento da personalidade: Enfoque psicodinâmico. Rio de Janeiro: Bertrand Brasil, 1996.

GANDRA, M. M. G. A importância da Inteligência Emocional nas competências de Gestão: Um estudo de caso num operador logístico português. Universidade Lusófona do Porto- Faculdade de Ciências Económicas, Sociais e da Empresa. Dissertação, 2016.

GARCIA, J. G. Conhece teu próximo como a ti mesmo. Joinville: Clube dos Autores, 2015.

GARDENSWARTZ, et. al. Inteligência emocional na gestão de resultados. Editora: Clio, 2012.

GARDNER, H. Inteligências múltiplas: A teoria na prática (M. A. V. Veronese, Trad.). Porto Alegre, RS: Artes Médicas, 1995.

GRAY, J.; ANNIS, B. Trabalhando juntos: homens e mulheres inteligentes. Tradução: Elvira Serapicos. São Paulo: Editora Paralela, 2013.

GOLEMAN, D. Trabalhando com a Inteligência Emocional. Rio de Janeiro: Objetiva, 2001.

GOLEMAN, D. Inteligência emocional: a teoria revolucionária que redefine o que é ser inteligente. Rio de Janeiro: Objetiva, 2017.

GOMES, R. A.; SIQUEIRA, M. M. Inteligência emocional de estudantes universitários. Psicólogo inFormação, ano 14, n. 14, jan./dez. 2010.

HERCULANO, S.C. Qualidade de vida e seus indicadores. In: Qualidade de Vida e Riscos Ambientais. Niteroi: Eduff, 2000.

HOUAISS, A.; VILLAR, M. S. Dicionário Houaiss da Língua Portuguesa. Rio de Janeiro: Objetiva, 2009.

JOBIM, A. C. B. de A.; MORAIS, M. V. da C. M. de. A felicidade. In: Raros compassos. [S.I.]: Revivendo, 2000.

JUNQUEIRA, F. C.; COUTO, E. S. A.; PEREIRA, M. K. S. A importância da inteligência emocional na atuação de um líder. VIII SEGeT - Simpósio de Excelência em Gestão e Tecnologia - 2011.

LAYARD, R. Happiness: Lessons from a new science. London: Penguin, 2011.

LOES, J. Qual o seu índice de felicidade? Disponível em: http://www.istoe.com.brreportagens. Acesso em: 16 maio 2014.

LYUBOMIRSKY, S.; LEPPER, H.S. A measure of subjective happiness: preliminary reliability and construct validation. Soc Indic Res 46: 137-155, 1999. 
LUSTOSA. A. E., MELO, L. F. N In: Conjuntura econômica goiana. Boletim Trimestral. n. 14 (2004), Goiânia: Secretaria do Planejamento e Desenvolvimento do Estado de Goiás, 2010, p. 36-40.

MACIEL, A. P.; SÁ de SOUZA, B. Liderança e inteligência emocional: ferramentas de apoio ao modelo de excelência em gestão pública. Trabalho de Conclusão de Curso. UFF, 2016

MARCONDES, L. F. B. B. Inteligência emocional e Bem-estar no trabalho de funcionários públicos. 2008. 54f. Trabalho de Iniciação Científica - Faculdade de Psicologia e Fonoaudiologia, Universidade Metodista de São Paulo, São Bernardo do Campo, 2008.

MARQUES, J. R. Inteligência emocional no trabalho, por que ela é tão importante? Instituto Brasileiro de Coaching-IBC, 2018 https://www.ibccoaching.com.br/portal/coaching-e-psicologia/inteligenciaemocional-trabalho-importante/

MATTHEWS, G., ZEIDNER, M., \& ROBERTS, R. D. Emotional intelligence: Science and myth. Cambridge, MA: Massachusetts Institute of Technology, 2002.

MAVROVELI, PETRIDES, SANGAREAU \& FURNHAM. Trait emotional intelligence psychological well-being and peer-rated social competence in adolescence. British Journal of Developmental Psychology, 25(2), p.263-275, 2009.

MAYER, J. D., \& SALOVEY, P. What is emotional intelligence? In: P. Salovey \& D. Sluyter (Eds.), Emotional development and emotional intelligence: Implications for educators (p. 03-31). New York: Basic Books, 1997.

NASCIMENTO, S. H. As relações entre Inteligência emocional e Bem-estar no trabalho. 2006. 95f. Dissertação (Mestrado em Psicologia da Saúde) - Faculdade de Psicologia e Fonoaudiologia, Universidade Metodista de São Paulo, São Bernardo do Campo, 2006.

OLIVEIRA, et. al. OS índices de bem estar e felicidade como alternativas para a mensuração do desenvolvimento dos países. VII Seminário de Pesquisa Interdisciplinar. UNICSUL, 2016.

PAIS-RIBEIRO, J. L. Validação transcultural da escala de felicidade subjectiva de Lyubomirsky e Lepper. Psicologia, Saúde \& Doenças, 2012, 13 (2), 157 - 168.

PEREIRA, C. A. A. Um panorama histórico-conceitual acerca das subdimensões de qualidade de vida e do bem-estar subjetivo. Arq Bras Psicol. 1997; 49(4):32-48.

PORTO, D.; MEDEIROS, R. A. A felicidade como elemento indicador de desenvolvimento social. 2017.

RAMM, D. Clinically formulated principles of morality. New Ideas in Psychology, 14, 237-256, 1996.

RYBACK, D. Emoção no local de trabalho: o sucesso do líder não depende só do Q.I. Tradução: Mirtes F. de Oliveira Pinheiro. 5 ed. São Paulo: Editora Cultrix, 2004. 
SALES, A. P. et al. Felicidade Interna Bruta: Um estudo na cidade de Lavras - MG. In: ENCONTRO DA ASSOCIAÇÃO NACIONAL DE PÓS-GRADUAÇÃO E PESQUISA EM ADMINISTRAÇÃO; 36. 2012, Rio de Janeiro. Anais..., Rio de Janeiro: ENANPAD, 2012, p. 1-16.

SANDRONI, P. Dicionário de economia. Nova edição revista e ampliada. 7.ed. São Paulo, 1987.

SANTOS, M. C. C. Inteligência emocional e criatividade: um estudo empírico. Faculdade de Economia da Universidade de Coimbra. Tese de doutorado, 2014.

SERRA, F. A terceira inteligência. São Paulo: Butterfly, 2004.

SILVA, B. M. M. A et. al. Inteligência Emocional na Liderança e Sua Relação com a Melhoria da Comunicação Interpessoal nas Organizações: Estado do Conhecimento no Seget. SEGeT XI Simpósio de Excelência em Gestão e Tecnologia, 2014.

TAVARES, L. INTELIGÊNCIA EMOCIONAL E A SATISFAÇÃO NO TRABALHO. Lisboa, $2013 . \quad$ Disponível em: $<$ recil.ulusofona.pt/bitstream/handle/10437/4864/Tese_Janeiro_. Acessado em: 25/10/2019.

URA, K.; ALKIRE, S.; ZANGMO, T.; WANGDI, K. An Extensive Analysis of GNH Index. Butão: Centro de Estudos do Butão, 2012.

URA, D.K. Gross National Happiness as a Larger Context for Healing and Global Change. Disponível em: < http://www.oecd.org/dataoecd/47/62/44120751.pdf >. Acesso em 25 de Abril de 2012.

VEENHOVEN, R. Advances in understanding happiness. Revue Québécoise de Psychologie, 18, 29-74, 1997.

VEENHOVEN, R. The four qualities of life: ordering concepts and measures of the good life. Journal of Happiness Studies, 1, 1-39, 2000.

WEISINGER, H. Inteligência Emocional no trabalho: como aplicar os conceitos revolucionários da I.E. nas suas relações profissionais, reduzindo o estresse, aumentando sua satisfação, eficiência e competitividade. Rio de Janeiro: Objetiva, 2001.

WELSCH, H. Implications of happiness research for environmental economics. Ecological Economics, v. 68, p. 2735-42, 2009.

WOYCIEKOSKI, C. \& HUTZ, C. S. Inteligência Emocional: Teoria, Pesquisa, Medida, Aplicações e Controvérsias. Psicologia: Reflexão e Crítica, 22(1), 1-11, 2009.

ZANELLI, J. C.; ANDRADE, J. E. B.; BASTOS, BITTENCOURT, A. V. (orgs.). Psicologia, organizações e trabalho no Brasil. 2 eds. Porto Alegre: Artmed, 2014. 